Artigos

DE

OPINIÃo 


\section{FATORES AMBIENTAIS DO CRESCIMENTO DA CRIANÇA}

\section{Eduardo Marcondes ${ }^{1}$}

\section{INTRODUÇÃO}

A Pediatria tem sido definida como a parte da Medicina que estuda o ser humano em crescimento e desenvolvimento, desde Q nascimento até a adolescência, inclusive. A ciência que estuda o crescimento (auxologia) é, pois, integrante da própria doutrina pediá ica e a vigilância do crescimento e desenvolvimento é a mais importante ação do pediatra.

O crescimento, encarado globalmente, é a solfataria de fenómenos celulares, bioqu nicos, biofísicos e morfogenéticos, cuja integração é feita segundo um plano predeterminado pela herança e modificado pelo ambiente. O estudo do crescimento da criança é, atualmente, $\sim \wedge \mathrm{un}^{\wedge} \mathrm{daI}^{\wedge} \mathrm{X}^{\wedge} \wedge$ lenta$\wedge$ lmente antropológico e, como tal, não considera o individuo objeto de estudo como padrão est tico no tempo e no espaço, mas, sim, trata de pôr em destaque suas diferenças, esmerando-se por estabelecer grupos naturais definidos de acordo com suas características, procurando averiguar o significado biopsicossocial de cada grupo.

Embora não se conheça ainda a intimidade do fenómeno crescimento, os dados antropométricos são de grande valia em Pediatria como indicadores de saude, pois:

a) Sem serem o fenômeno, podem representá-lo;

b) São passíveis de expressão numérica;

c) Suas principais limitações são conhecidas; e

d) Podem ser obtidas por pessoal não-médico.

Do ponto de vista social, a estatura dos indivíduos de uma comunidade é um bom indicador do estado de saúde de toda a população; índice melhor, segundo Tanner, do que o produto bruto nacional. Estatura é status, o cartão de visita biológico do indivíduo e a baixa estatura pode ser considerada co» um desastre biológico.
O crescimento é um atributo indelével dos organismos jovens, sejam seres humanos, animais ou plantas. Na espécie humana, depende da interação homem/ambiente, aquele representado pela sua constituição ("existência de modos individuais genéticos de ser e de reagir”) e este pela totalidade dos fatores que cercam o indivíduo, bióticos, abióticos e psicossociais. Poder-se-ia dizer que o homem possui a capacidade genotfpica ou constituirão individual e que, de sua interação com os fatores ambientais, resulta a capacidade fenotfpica ou vitalidade.

De acordo com as normas do Departamento de Pediatria da Faculdade de Medicina da Universidade de São Paulo, a estatura normal é a que se localiza entre os percentis 2,5 e 97,5 segundo o referencial adotado ("Padrão Santo André”). O canal de vigilancia para baixa estatura é delimitado pelos percentis 10,0 e 2,5.

As causas da baixa estatura são múltiplas e podem ser distribuidas em três grupos:

1. Baixa estatura de causa familiar.

2. Baixa estatura decorrente de doenças ligadas aos fatores intrínsecos, organicos ou individuais do crescimento: doenças genéticas (gênicas ou crornossômicas), neuro-endócrinas e primárias do esqueleto.

3. Baixa estatura decorrente de agravos ligados aos fatores extrínsecos, ambientais ou populacionais do crescimento: agravos nutricionais e psicossociais, doenças que comprometem a economia corpórea como um todo (baixa estatura visceral) e baixa estatura ao nascer.

A presente publicação, em sua versão original, diz respeito a dois importantes aspectos do crescimento: fatores ambientais e rnonitorização.

Os fatores arnbientais do crescimento são da máxima importancia; pode-se dizer que o crescimento da criança é enfaticamente ambiente-dependente. Como os fatores organicos são normais ao nascimento na quase totalidade dos recém-nas-

1 Professor titular de Pediatria (aposentado) da Faculdade de Medicina da Universidade de São Paulo, integrante do Grupo de Assessoria Pedagógica da FMUSP e coordenador do Programa de Avaliaço Curricular.. 
cidos, pode-se afirmar que o desastre biológico, citado antes a propósito da baixa estatura, é sobretudo um desastre ecológico no vasto campo da ecologia humana.

A monitorização do crescimento é uma das ações básicas de saúde no atendimento primário à criança, juntamente com o aleitamento materno, as imunizações e a terapia de reidratação oral (Alma Ata, 19^?8).

É um procedimento indispensável e insubstituível na assistência à criança, pois permite acompanhar, avaliar e controlar o crescimento da criança com vistas à promoção da saúde, do desenvolvimento humano e da qualidade de vida.

\section{ASPECTOS GERAIS DA ECOLOGIA}

Ecologia é o ramo das ciências humanas que estuda a estru lura e o desenvolvimento das comunidades humanas em relações com o meioambiente e sua consequente adaptação a ele, assim como novos aspectos que os processos tecnológicos ou os sistemas de organização social possam acarretar para as condições de vida do homem.

O ambiente é constituído pela totalidade dos fatores bióticos (os animais e as plantas), abióticos (de natureza fundamentalmente físicoqu nica, como a atmosfera, a água, o solo, o clima, a geomorfologia e outros) e psicossocioculturais. Com esses elementos, estrutura-se a unidade de estudo em ecologia - o ecossistema , definido como a totalidade de fatores que se interrelacionam em um determinado lugar da biosfera.

A ecologia humana estuda os fenómenos ambientais em função do indivíduo e das comunidades humanas: além dos fatores bióticos e abióticos, ela enfatiza os fatores psicossocioculturais relacionados com a organização da sociedade, surgindo, então, a valorização das abstrações, dos simbolos, das crenças e dos valores. Como escreve Carcavallo, o homem não só modificou profundamente os ecossistemas, como sobretudo criou o seu próprio sistema, o antropossistema:

\footnotetext{
... distinto e antagónico em relação aos anteriormente formados pela natureza. Ignora as características que definem um ecossistema e os substitui por campos de monoprodução; mata todas as espécies vegetais e animais de uma área e semeia uma única espécie; queima uma selva de mil espécies de reino natural para reflorestá-la (se é que o faz!), com uma única espécie de rápido rendimento madeireiro; inumda enormes extensões da biosfera para obter quilowatts de energia elétrica para suas indústrias; nas cidades (o
}

antropossistema $\mathrm{m} \sim$ ximo), os únicos vegetais existentes são omamentais e os únicos an nais são cachorros, gatos e algumas aves e os que até agora sobreviveram à matança do homem: roedores e uns poucos artrópodes.

Na Tabela 1 apresentam-se as principais diferenças entre o ecossistema e o antropossistema, segundo Bennett e Carcavallo.

Tabela 1 - Diferenças entre o ecossistema e o antropossistema (segundo Bennett e Carcavallo).

\begin{tabular}{|c|c|c|}
\hline Características & Ecossistema & Antropossistema \\
\hline 1. Variedade de espécies & grande & ausente \\
\hline 2. Informaçâo genética & rica & uniforme \\
\hline $\begin{array}{l}\text { 3. Estabilidade tempo- } \\
\text { rospacial }\end{array}$ & $\operatorname{sim}$ & não \\
\hline 4. Regulação e controle & autógena & a cargo do homem \\
\hline 5. Suficiência material & autógena & $\begin{array}{l}\text { necessidades de } \\
\text { aportes constantes }\end{array}$ \\
\hline 6. Fonte energética & solar & $\begin{array}{l}\text { pluralidade de fon- } \\
\text { tes }\end{array}$ \\
\hline 7. Dinâmica populacional & $\begin{array}{l}\text { relacionada } \\
\text { ao ambiente }\end{array}$ & $\begin{array}{l}\text { não relacionada } \\
\text { ao ambiente }\end{array}$ \\
\hline $\begin{array}{l}\text { 8. Metabolizaçẩo sistêmi- } \\
\text { ca de matéria e energia }\end{array}$ & completa & incompleta \\
\hline 9. Informaçāo semântica & escassa & $\begin{array}{l}\text { rica, em contínua } \\
\text { acumulaçāo }\end{array}$ \\
\hline 10. Biomassa & $\begin{array}{l}\text { ótima, de espécies } \\
\text { inter-relacionadas }\end{array}$ & $\begin{array}{l}\text { máxima de espécies } \\
\text { pouco ou nada } \\
\text { inter-relacionadas }\end{array}$ \\
\hline 11. Alteraçōes estruturais & $\begin{array}{l}\text { muito lentas } \\
\text { (séculos ou milênios) }\end{array}$ & $\begin{array}{l}\text { muito rápidas (em } \\
\text { alguns casos, se- } \\
\text { gundos) }\end{array}$ \\
\hline $\begin{array}{l}\text { 12. Retroalimentaçăo sis- } \\
\text { têmica }\end{array}$ & constante & $\begin{array}{l}\text { inconstante, insuff- } \\
\text { ciente e variável }\end{array}$ \\
\hline 13. Cadeias energéticas & $\begin{array}{l}\text { fundamentalmente } \\
\text { tróficas }\end{array}$ & $\begin{array}{l}\text { fundamentalmente } \\
\text { não tróficas }\end{array}$ \\
\hline 14. Energia utilizada & $\begin{array}{l}\text { em quantidade } \\
\text { necessária e suficien- } \\
\text { te para a manutenção } \\
\text { da vida }\end{array}$ & $\begin{array}{l}\text { desperdício, sem } \\
\text { relação com as } \\
\text { necessidades vitais }\end{array}$ \\
\hline $\begin{array}{l}\text { 15. Emprego de elemen- } \\
\text { tos químicos }\end{array}$ & $\begin{array}{l}\text { relacionado com } \\
\text { moléculas e ativida- } \\
\text { des orgânicas }\end{array}$ & $\begin{array}{l}\text { nâo relacionado } \\
\text { com moléculas e ati- } \\
\text { vidades orgânicas }\end{array}$ \\
\hline $\begin{array}{l}\text { 16. Relaçáo com água, } \\
\text { solo e ar }\end{array}$ & estreita & escassa \\
\hline 17. Crescimento ilimitado & impossivel & $\begin{array}{l}\text { explosão demográ- } \\
\text { fica humana }\end{array}$ \\
\hline 18. Autodestruiçāo & não & $\operatorname{sim}$ \\
\hline 19. Símbolos abstratos & inexistente & $\begin{array}{l}\text { existente, } \\
\text { imprescindível e em } \\
\text { constante criação }\end{array}$ \\
\hline 20. Agressão & $\begin{array}{l}\text { nấo agride } \\
o \text { antropossistema }\end{array}$ & $\begin{array}{l}\text { agride, modifica e } \\
\text { destrói o ecossistema }\end{array}$ \\
\hline
\end{tabular}

A ecologia humana preocupa-se tanto com o ecossistema como com o antropossistema, pois, para a saúde do homem, aí bos se completam, para o bem ou para o mal. A doença é conseqüência da inexistência, insuficiência ou ineficiência dos mecanismos adaptativos do indivíduo ou do grupo a que pertence, o que pode ser analisado à luz de alterações na entrada do sistema $\sim \mathrm{i} \sim \mathrm{u} \sim 3$, no manejo ou incorporação do agente e/ou da informa mação, na saída (output) e no retromuniciamento (feedback). O esquema é válido para a do- 
ença de um individuo ou de populapões. Alguns exemplos:

- A distrofia por carência se deve a uma insuficiente en ada de material nutricional e/ou mau aproveitamento ou má distribuição do mesmo e/ou excesso de saída. Sabe-se que, nesse caso, ão fundamental é a presença de falares sociais e económicos que não permitam a corveta distribuição do material alimentar dentro do sistema (o antropossistema comprometendo a viabilidade do ecossistema)

- A delinquência juvenil é uma doença social devida a um desajuste adaptativo individual em relação ao ambiente. Do ponto de vista ecológico, trata-se de anomalia de fluxo de informação, com ingresso superior à capacidade de metabolização, pelo indivíduo e pela sociedade. A publicidade e a propaganda promovem a valorização de bens de consumo que acabam por constituir-se em simbolos de condição social.

- A comunicação ambiental é a incapacidade sistêmica de metabolizar um fluxo (não obrigatoriamente aumentado) de matéria, ou de energia, ou de informação (respectivamente, DDT, resíduo atómico e ruido, como exemplos).

Nem mesmo o homem-físico é o mesmo em todas as latitudes e longitudes, embora possamos admitir que as variabilidades biológicas sejam de pequena amplitude. Diferentes genótipos, resistências e vulnerabilidades específicas e a eventual presença de tais ou quais doenças não ligadas ao ambiente fazem com que o indivíduo, sempre que possfvel, deva ser considerado como ele mesmo.

E que dizer da variabilidade do ambiente, a soma dos agentes bióticos, abióticos e psicossocioculturais? A compreensão das combinações possíveis escapa à capacidade da mente humana! Contudo, o médico há de se esforçar, na assistência prestada para detectar tais ou quais fatores ambientais, estes favoráveis e aqueles desfavoráveis, uns devendo ser preservados pelo que representam de proteção ao indivíduo e outros minimizados o quanto possível por constituírem agravos à saúde.

A tarefa poderá ser facilitada à medida que prevalecer o conceito de nichos ecológicos, isto é, um conjunto de falares asno bientais referente a um espaço reduzido, porém marcante, para a saúde do indivíduo. Para cada nicho ecológico urge estipular os melhores padrões de saúde para aquelas condições. Monge chama a atenção para esse aspecto, questionando inclusive o conceito que ele chama de "normalidade internacional" (como referido nos livros) com desconhecimento das características do nicho ecológico, sejam elas físicas ou psíquicas. Pergunta o autor se é real- mente verdade que os níveis normais de hemoglobina no homem sejam de 15,0 g por 100 mi de sangue somente porque são os valores constantes nos Tratados de Medicina: se for verdade, como fica a situação das pessoas que vivem em um nicho ecológico especial, o altiplano boliviano? Monge afirma:

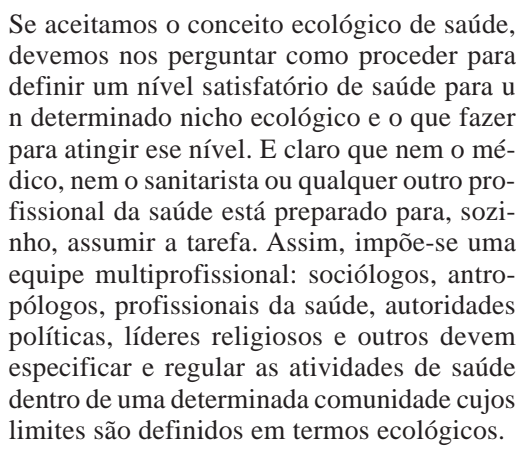
definir um nível satisfatório de saúde para u n determinado nicho ecológico e o que fazer para atingir ese nível. E claro que nem o médico, nem o sanitarista ou qualquer outro profissional da saúde está preparado para, sozinho, assumir a tarefa. Assim, impõe-se uma equipe multiprofissional: sociólogos, antropólogos, profissionais da saúde, autoridades políticas, líderes religiosos e outros devem especificar e regular as atividades de saúde dentro de uma determinada comunidade cujos limites são definidos em termos ecológicos.

Assim vai o ser humano interagindo no decurso de sua existência com o conteúdo biótico, abiótico e psicossociocultural de variados nichos ecológicos. Melhor será substituir, então, a conhecida relação honzenz/ambien e por outra relação, um pouco mais trabalhada:

\begin{tabular}{c|c} 
HOMEM & constituição \\
(modo de ser e de reagir) & GICHOECOLÓ-
\end{tabular}

E como fica a criança nesse contexto?

Penso que o relacionamento da criança com o seu ambiente tem uma importância que transcende a verificada para o adulto, tendo em vista a característica ímpar dos seres vivos jovens, o crescer e o desenvolver, a partir de um ponto de vulnerabilidade máxirna, decrescente ao longo do processo de crescimento, mas relevante por muitos anos. Quanto mais jovem a criança, mais dependente do ambiente: $\mathrm{o}$ adulto reage, briga, foge ou mata na busca de sua adaptação e a criança é muitas vezes inerme em relação ao meio. Se Robinson Crusoé fosse criança, sua história seria bem curta!

Reproduzo as palavras de Pedro de Alcantara ao discutir a forma da dependência da criança em relação ao meio e as conseqüentes responsabilidades da sociedade.

Na gestação normal, a criança de equipamento genético favorável vive em condições ímpares de segurança: inércia respiratória, digestiva, de absorção intestinal, de eliminação de escórias, de termorregulação; limitação de movimentos; proteção quase completa contra os traumas físicos; ausência de traumas psíquicos. 
Mas a vida, como a saúde, resulta do valor da relação entre a resistência do organismo e os obstáculos ou agravos que ele tem que enfrentar. Acabada de nascer a criança, seu impulso vital tem a mesma intensidade imediatamente anterior, mas agora vai funcionar em condições de vida muito diferentes e, com frequência, adversas. Grande número de funções, até então em condições potenciais, é convocado ao trabalho. A diversidade das novas condições de vida, aliada à inércia anterior dos mecanismos de adaptação, cria o grande caráter da criança, sua vulnerabilidade, a qual exige peculiaridades assistenciais que promovam sua adaptaçao àquelas condições.

Essa adaptação pode ser esquematizada nos seguintes setores:

1. Função nutritiva, atuante na vida intrauterina quanto ao metabolismo celular, mas inoperante quanto à preensão dos alimentos, à sua digestão e absorção e à eliminação de escóriastudo isso se fazendo através da placenta.

2. , cujo componente afetivo é altamente vulnerável desde o nascimento e sujeito, a partir de então, a nocivos sofrimentos pela perda das regalias da vida intra-uterina, pela inibição educativa dos impulsos instintivos, pelas contradições que a criança tem que enfrentar, pelas emoções súbitos e penosas que decorrem de falares ambientais fortuitos e pelos erros de conduta dos adultos que criam ou intensificam esses falares de sofrimento.

3. Função imunitária, para a qual a criança nasce dotada apenas de imunidade inespecífica, proporcional à sua resistência constitucional, e de imunidade especifica passiva transplacentária e transitória, apenas para algumas poucas infecções.

4. Ambiente físico, cujos caracteres (temperatura, umidade, ventilação, luminosidade, ruídos, odores) apresentam variações por vezes bruscas, intensas e frequentes, bem como valores permanentes muito acentuados, tudo muito diverso da "monotonia" ambiente da vida intra-uterina.

5. Oportunidades de acidentes, para os quais a criança é, no início, totalmente autoindefesa.

A importância da mãe na ecologia da criança é de tal magnitude que Wolanski a conceitua como falar paragenético (genes não transmitidos), não só em função da influência dos traços constitucionais da mãe sobre a formação da personalidade do filho, mas também em relação às características metabólicas do organismo da mãe capazes de influir no crescimento fetal.

Assim, a tradicional divisão dos fatores do crescimento em genéticos (ou intrínsecos) e ambientais (ou extrínsecos),

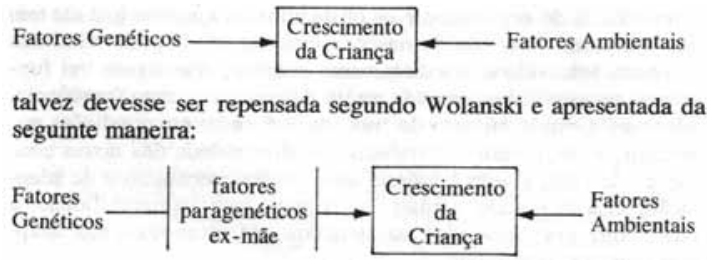

Wolanski também lembra a existência de uma verdadeira interfase entre a heranca e o ambiente: é o modo de vida, o ponto de encontro de muitos traços herdados com muitas características ambientais. Atividades motores, tempo de sono, postura, engorda. Explicitando: há famílias de insones (herança), mas o pouco dorrnir é intensificado pelo assistir TV (ambiente); há faz ias de atletas (herança), mas 0 viver com pouca atividade física pode ser decorrência de falta de local para práticas esportivas, coisa frequente nas grandes cidades (ambiente); há pessoas com predisposição para engordar (herança), mas só o farão se houver generosa oferta de alimentos associada a maus hábitos alimentares (ambiente). Enfatizase a postura que, quando incorrera, ocasiona distúrbios das vísceras, hipóxia cerebral e retardo do desenvolvimento físico: uma criança pode apresentar importantes problemas em decorrência da má postura na escola (onde ela passa várias horas por dia, um nicho ecológico de grande importância) em virtude de mobiliário inadequado.

O esquema apresentado a seguir deve ser, então, aceito como uma visão mais abrangente dos falares do crescimento, muito útil para o propósito deste artigo.

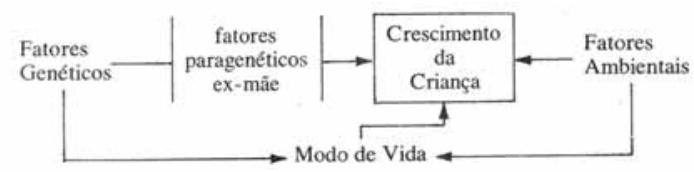

A ecossensibilidade é variável de pessoa para pessoa bem como para uma mesma pessoa em função do tempo. As evidências mostram que a maior sensibilidade ocorre quando o processo de crescimento e desenvolvimento é mais rápido e/ou quando a atividade metabólica dos tecidos é mais intensa: decorrência natural, os momentos de maior ecossensibilidade para o ser humano parecem ser os primeiros quatro ou cinco anos de vida e a puberdade.

Outro aspecto-muito importante: admitese (segundo Wolanski) que os organismos homozigotos (ou, melhor dito, as características determinadas em um dado indivíduo por genes homólogos) são menos sensíveis aos estímulos ambientais do que os heterozigotos. Assim, demonstra-se que a progenia heterozigosidade é mais alta do que a progenia homozigótica, em iguais 
condições de nutrição. E é forçoso reconhecer que o fenómeno da heterozigosidade em nível populacional está crescendo, como resultado das correntes migratórias e a minimização das comunidades isoladas. Portanto, vemos um aumento da ecossensibilidade, em função do crescente apequenamento do nosso mundo.

Quais as perspectivas ecológicas para as crianças que estão nascendo agora? seguinte:

Para a reflexão dos leitores, sugere-se o

1. Aumento absoluto de estimulas ambientais independente de sua qualidade (benéfica ou maléfica).

- estímulos físicos, através do aparecimento de novas substanciar químicas e da crescente poluição do ar, da água e do solo, bem como do resíduo atômico;

- estímulos psicossocioculturais, através do avanço das comunicações, das redefinições políticas e sociais e da cruscente permissividade.

2. Aumento da ecossensibilidade. lação;

- crescente taxa de heterozigose na popu-

- urbanização.

3. Diminuição progressiva das atividades mataras em decorrência da automação, da monitorização e do confinamento, do que resultará uma vida sedentário cada vez mais presente e uma diminuicão do potencial de resistência do organismo. bióticos.

4. Controle de alguns fatores ambientais

5. Conseqüências ainda imprevisíveis da energia nuclear e das viagens interplanetárias.

\section{FATORES AMBIENTAIS}

Os fatores ambientais que influenciam o crescimento são incontáveis e em contínua variabilidade, o que obriga o indivíduo a uma constante adaptação fisiológico.

Variáveis sócio-econômicas exercem importante influência no crescimento: renda par capita, idade dos pais, tamanho da família, condições de habitação e de saneamento, escolaridade e cultura dos pais. Uma investigação do Instituto da Criança de São Paulo com 1.010 crianças faveladas de zero a doze anos de idade mostra claramente a devastação que as más condições sócioeconômicas de vida determinam em relação ao crescimento das crianças. Os dados referentes à altura revelam grave situação. Sobretudo a partir dos dois anos de idade, a média aritmética da estatura bordeja o limite inferior da normalidade e, por outro lado, o li- mite inferior da população favelada mostra situação desalentadora. A situação referente ao peso é mais animadora, o que sugere baixa estatura residual com eventual supuração dos fenómenos da fase acuda da desnutrição.

A população que encontramos espalhada pelas favelas estudadas é fruto de fluxo rural-urbano. Hoje, essa população, normalmente designada por "população marginal”, corresponde aos resultados de uma situação nas áreas rurais, a que os demógrafos chamam de "repulsiva" e que, no quadro da sociedade brasileira, se faz presente a partir

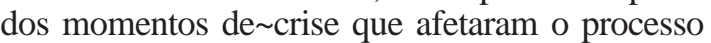
monocultor regional ao longo da história do período colonial, dando origem à chamada "plebe rural”.

Essa população, caracterizada por uma tópica marginalidade em relação à vida económica, sócio-cultural e politico-institucional, agrupa-se em torno de um conjunto subnormal de habitações instaladas em terrenos abandonados ou em litígio, ou de propriedade do poder público, geralmente insalubres, aparecendo a madeira, a lata, o zinco e o papelão como materiais de construção.

A saúde é um estimulante fundamental para o crescimento; consequentemente, o mau funcionamento do organismo como um todo, ou através dos principais territórios de sua economia, é uma causa importante de baixa estatura, constituindo o grupo assim chamado visceral. O nome é bastante sugestivo no sentido de não incluir as doenças das glandulas endócrinas (pois não são consideradas vísceras) e do esqueleto, bem como os agravos diretos à nutrição da criança.

Inúmeras doenças de origem ambiental comprometem o crescimento da criança, sobretudo por agentes físicos bióticos.

Os mecanismos através dos quais uma doença visceral compromete o crescimento são complexos e vários tipos de agravos podem atuar concomitantemente. Os seguintes conjuntos são importantes:

1. Comprometimento direto dos músculos, ossos e articulações.

- doenças primárias da musculatura,

- infecções (miosites, artrites e osteomielites),

- poliomielite,

- traumatismos.

2. Comprometimento indireto na nutrição (prejuízo da deglutição, digestão, absorção, metabolizaçáo, consumo e excreção de nutrientes).

- infecções,

- parasitoses intestinais,

- neoplasias,

- intoxicações.

3. Prejuízo da oxigenarão dos tecidos. - anemias, 
- cardiopatias,

- pneumopatias.

4. Obrigatoriedade de repouso prolongado.

5. Obrigatoriedade de determinados tratamentos, como, por exemplo, cortisonoterapia.

Estudo em crianças guatemaltecas mostrou que a frequiência e a intensidade de episódios diarréicos guarda relação com palrados de desaceleração do crescimento, o que não foi observado em relação a doenças respiratórias: enfatizam mais estes aspectos em relação à importância social da síndrome diarréica. Tolentino propõe a lei da prevalência, segundo a qual o organismo, em situação de emergência pela presença de processo infeccioso, deriva calorias para o combate à infecção em prejuízo do crescimento.

Suprimido o processo mórbido causador da interrupção do crescimento, a criança apresentará um período de crescimento acelerado, a fim de retomar seu padrão anterior à doença. O cresc mento é como um projétil teleguiado, sob o controle de complexos sistemas que se enquadram definitivamente na cibernética. Uma questão totalmente a resolver é a maneira pela qual o organismo sabe quando desacelerar a fase do crescimento intensa após um período crítico de desaceleração decorrente de inúmeros agravos. A capacidade dos indivíduos em crescimento de retomarem seus padrões evolutivos quando deles afastados, deu-se o nome de homeorrese (rhe-fluir).

Marshall, analisando as variações geográficas e étnicas do ser humano, comenta as variações das proporções corpóreas, como, por exemplo, o comprimento dos membros inferiores e as diferenças de distancias bio-acromiais e bi-cristais ilíacas.

Sabe-se que o segmento superior é mais ecorresistente do que o segmento inferior. Predição da altura final em função do segmento superior é o "mínimo potencial genético da estatura final”; já a predição em função do segmento inferior é o "máximo dano ambientar possível de ser sofrido" e a predição considerando a estatura to- tal é o "máximo objetivo a ser atingido". As predições com base no segmento superior (ecorresistente) parecem anunciar as diferenças entre classes sócio-econômicas.

A seguir serão analisados três delatores ambientais de grande iinportancia auxológica: nutrição, estimulação biopsicossocial e atividade física. E no final, comentários sobre a variação secular do crescimento.

\section{Nutrição}

Como todo esforço, o crescimento consome energia: $40 \%$ das calorias fornecidas Normalmente à criança no primeiro ano de vida são destinadas ao crescimento. No final do primeiro ano, essa cifra baixa a $20 \%$. A dieta deve ser suficiente em calorias e equilibrada em suas proporções, sem o que não haverá crescimento normal.

Deve-se fornecer energia a uma criança para atender as necessidades de:

a) metabolismo basal;

b) ação dinaâmico-especíica dos alimentos;

c) atividade muscular; e

d) crescimento.

O metabolismo banal consome proporcionalmente menos calorias conforme a criança aumenta de idade. o "custo calórico" dos alimentos (ação dinâmico-específica) varia com a dieta, sendo proporcionalmente mais elevado quando aumenta a taxa de proteínas da dieta, mas é importante lembrar que proteína incorporada para o crescimento está livre da ação dinamico-especffica A parte referente à atividade muscular varia muito de indivíduo para indivíduo, em diferentes idades e conforme o sexo. A taxa calórica reservada ao crescimento varia com a idade, tendo em vista a desaceleração do mesmo. Nos prematuros, as necessidades calóricas para o crescimento podem ser duas vezes as do recém-nascido normal. $\mathrm{Na}$ Tabela 2 estão as necessidades calóricas médias por quilo de peso para os diferentes setores em diferentes idades.

Tabela 2 - Necessidades calóricas totais em cal $/ \mathrm{kg}$ de peso corpóreo.

\begin{tabular}{l|c|c|c|c}
\hline \multicolumn{1}{c|}{ Setores } & $\begin{array}{c}\text { Recém- } \\
\text { nascido }\end{array}$ & Lactente & $\begin{array}{c}\text { Pré-escolar/ } \\
\text { Escolar }\end{array}$ & Adulto \\
\hline Metabolismo basal & 35 & 55 & 35 & 25 \\
Crescimento & 25 & 25 & 10 & 0 \\
Atividade & 10 & 25 & 25 & 10 \\
A.D.E. & 10 & 10 & 10 & 5 \\
\hline Total & $\mathbf{8 0}$ & $\mathbf{1 1 5}$ & $\mathbf{8 0}$ & $\mathbf{4 0}$ \\
\hline
\end{tabular}


Tem-se dito que "crescer é sinônimo de proteinizar”, isto é, reter nitrogênio. A proteína é o material único insubstituível e fundamental do crescimento e da reconstrução incessante: a albumina leva em si a excelência do crescimento. O nitrogénio como elemento específico de crescimento não se acumula em depósito como ocorre com os hidratos de carbono e as gorduras, mas destina-se em sua quase totalidade para a histogênese. Cada $30 \mathrm{~g}$ de aumento de peso corpóreo necessitam 6,25 g de albumina, que correspondem a $1 \mathrm{~g}$ de nitrogénio.

As gorduras, além de serem fonte poderosa de energia, constituem material indispensável para a constituição de protoplasma (como fosfolípides, por exemplo), são veículos de vitaminas lipossolúveis (vitaminas A, D, E e K), contribuem para o sabor da dieta e a sensação de saciedade, são essenciais para a síntese de esteróides. Os ácidos graxas não saturados são essenciais, visto que o organismo não os sintetiza. Dietas normais, exceto pelo baixo teor de gorduras, falharam em promover um crescimento e desenvolvimento normais. Provou-se em experimentação animal que o ácido linoléico (algumas vezes referido como vitamina F) é essencial para o crescimento.

Quanto aos minerais, a criança necessita de pelo menos 12 minerais em quantidade adequada para a formação de novos tecidos. Entretanto, seis deles tom uma ação mais direta: cálcio, fósforo e magnésio pela contribuição importante e fundamental-na formação de tecido ósseo, influenciando por isso na altura do indivíduo; potássio por ser elemento intracelular e indispensável na formação protoplasmática; ferro por ser indispensável na formação de hemoglobina e, finalmente, iodo, que participa de um dos harmónios mais diretamente ligados ao crescimento, o harmónio tireoidiano.

Todas as vitaminas são indispensáveis para o crescimento, mas as vitaminas A, D e C têm ação mais evidentes sobre o crescimento e desenvolvimento; todo o complexo B também alua sobre o crescimento, porém de maneira menos direta.

A vitamina A participa ativamente no crescimento pois é um falar estimulante das células endoteliais da zona de ossificação e regulador da atividade osteoblástica. Na zona de cartilagem epifisária não há alinhamento normal das células quando falta vitamina A, o que determina alteração de ritmo de crescimento.

Basicamente a vitamina D favorece a absorção intestinal de cálcio, a reabsorção tubular de fósforo e a formação de matriz 6ssea; além disso, provoca a mobilização do cálcio a partir dos ossos e influencia positivamente a reabsorção tubular de aminoácidos. Na carência de vitamina D ocorre fundamentalmente uma desarmonia entre as cifras de calcemia e fosfatemia, com produto cálcio e fósforo inferior a 40; nessas condições, não há deposição da hidroxiapatita sobre a matriz 6ssea, ocorrendo maior estimulação da atividade osteoblástica da qual resulta a formação excessiva de tecido osteóide e o aumento da atividade da fosfatase alcalina.

A vitamina $C$ exerce influência marcante sobre o crescimento. É tão importante sua função, que se pode estabelecer um paralelismo entre atividade metab61ica dos 6rgãos e seu conteúdo de ácido ascórbico. E indispensável para a manutenção da substancia intercelular do tecido conetivo, ossos e dentes. Sua carência determina alteração da osteogênese endocondral e nos estudos graves de carência há interrupção do crescimento, já que nessas condições os osteoblastos são incapazes de formar matriz 6ssea. Demonstra-se, então, urna rarefação 6ssea, substituição da medula óssea por tecido fibroso e desprendimento do periósteo.

A Tabela 3 informa sobre as necessidades nutricionais diárias de crianças e adolescentes.

Em seguida, apresentam-se alguns dados sobre a baixa estatura de causa nutricional com ênfase na desnutrição (distrofia carencial protêicoenergética primária).

Além da dieta carente, há agravos ambientais importantes representados principalmente por infecções e infestações graves e repetidas. $\mathrm{O}$ abandono psicossocial pode ser tão grave que alguns autores sugerem a existência de dois tipos de desnutrição primária. O primeiro, dito sócio-econômico, resultante da miséria e do analfabetismo e o segundo tipo, dito sócio-cultural, devido a condições culturais adversas, prevalente em comunidades pseudoindustrializadas que retiveram em parte os valores culturais de uma vivência agrária em choque permanente com os valores decorrentes da urbanização caótica e da industrialização, do que resulta a desagregação familiar com ruptura do equilibrio bioecológico.

Inicialmente, o prejuízo da estatura é menos intenso do que o do peso em decorrência da utilização dos escassos nutrientes, segundo uma hierarquia de modo a certos tecidos e certas funções serem preservadas mais tempo. Assim, a perda de peso inicial constitui a homeosta e irnediata, a desaceleração ulterior do ganho de altura é a homeostase mediata e a diminuição do metabolismo basal, a hipotermia, a imobilidade e a hipotrofia, seguida de atrofia de tecidos e 6rgãos, é a homeostase tardia (Ramos Galvan). 
Tabela 3 - Recomendaçôes nutricionais diárias baseadas no informe do Comitê misto FAO/OMS de especialistas (1973).

\begin{tabular}{|c|c|c|c|c|c|c|c|c|c|c|c|c|c|}
\hline \multirow{2}{*}{ Idade } & \multicolumn{2}{|c|}{ Energia } & \multirow{2}{*}{$\begin{array}{c}\text { Proteína } \\
\text { (g) }\end{array}$} & \multirow{2}{*}{$\begin{array}{c}\text { Vit. A } \\
(\mu)^{*}\end{array}$} & \multirow{2}{*}{$\begin{array}{l}\text { Vit. D } \\
(\mu)^{* *}\end{array}$} & \multirow{2}{*}{$\underset{(\mathrm{mg})}{\text { Tiamina }}$} & \multirow{2}{*}{$\begin{array}{c}\text { Ribo- } \\
\text { flavina } \\
\text { (mg) }\end{array}$} & \multirow{2}{*}{$\underset{(\mathbf{m g})}{\text { Niacina }}$} & \multirow{2}{*}{$\begin{array}{c}\text { Ácido } \\
\text { Folico } \\
(\mu)\end{array}$} & \multirow{2}{*}{$\begin{array}{c}\text { Vit. D12 } \\
(\mu)\end{array}$} & \multirow{2}{*}{$\begin{array}{c}\text { Ácido } \\
\text { Ascórbico } \\
\text { (mg) }\end{array}$} & \multirow{2}{*}{$\begin{array}{c}\text { Cálcio } \\
\text { (g) }\end{array}$} & \multirow{2}{*}{$\begin{array}{c}\text { Ferro } \\
\text { (mg) }\end{array}$} \\
\hline & (kcal) & (MJ) & & & & & & & & & & & \\
\hline $\begin{array}{l}\text { Lactentes } \\
<6 \text { meses } \\
6-12 \text { meses }\end{array}$ & $\begin{array}{l}117 / \mathrm{kg} \\
108 / \mathrm{kg}\end{array}$ & $\begin{array}{l}0,49 / \mathrm{kg} \\
0,45 / \mathrm{kg}\end{array}$ & $\begin{array}{l}2,2 / \mathrm{kg} \\
2,0 / \mathrm{kg}\end{array}$ & $\begin{array}{l}420 \\
400\end{array}$ & $\begin{array}{l}10,0 \\
10,0\end{array}$ & $\begin{array}{l}0,3 \\
0,3\end{array}$ & $\begin{array}{l}0,4 \\
0,6\end{array}$ & $\begin{array}{l}5,0 \\
8,0\end{array}$ & $\begin{array}{l}50 \\
50\end{array}$ & $\begin{array}{l}0,3 \\
0,3\end{array}$ & $\begin{array}{l}35 \\
35\end{array}$ & & $\begin{array}{l}10 \\
15\end{array}$ \\
\hline $\begin{array}{l}\text { Crianças } \\
<1 \text { ano } \\
1-3 \text { anos } \\
4-6 \text { anos } \\
7-9 \text { anos }\end{array}$ & $\begin{array}{r}820 \\
1.360 \\
1.830 \\
2.190 \\
\end{array}$ & $\begin{array}{l}3,4 \\
5,7 \\
7,6 \\
9,2\end{array}$ & $\begin{array}{l}14 \\
16 \\
20 \\
25\end{array}$ & $\begin{array}{l}300 \\
250 \\
300 \\
400\end{array}$ & $\begin{array}{r}10,0 \\
10,0 \\
10,0 \\
2,5\end{array}$ & $\begin{array}{l}0,3 \\
0,5 \\
0,7 \\
0,9\end{array}$ & $\begin{array}{l}0,5 \\
0,8 \\
1,1 \\
1,3\end{array}$ & $\begin{array}{r}5,4 \\
9,0 \\
12,1 \\
14,5\end{array}$ & $\begin{array}{r}60 \\
100 \\
100 \\
100\end{array}$ & $\begin{array}{l}0,3 \\
0,9 \\
1,5 \\
1,5\end{array}$ & $\begin{array}{l}20 \\
20 \\
20 \\
20\end{array}$ & $\begin{array}{l}0,5-0,6 \\
0,4-0,5 \\
0,4-0,5 \\
0,5-0,5\end{array}$ & $\begin{array}{l}5-10 \\
5-10 \\
5-10 \\
5-10\end{array}$ \\
\hline $\begin{array}{l}\text { Adolescentes } \\
\text { (sexo masculino) } \\
10-12 \text { anos } \\
13-15 \text { anos } \\
16-19 \text { anos }\end{array}$ & $\begin{array}{l} \\
2.600 \\
2.900 \\
3.070\end{array}$ & $\begin{array}{l}10,9 \\
12,1 \\
12,0\end{array}$ & $\begin{array}{l}30 \\
37 \\
33\end{array}$ & $\begin{array}{l}575 \\
725 \\
750\end{array}$ & $\begin{array}{l}2,5 \\
2,5 \\
2,5\end{array}$ & $\begin{array}{l}1,0 \\
1,2 \\
1,2\end{array}$ & $\begin{array}{l}1,6 \\
1,7 \\
1,8\end{array}$ & $\begin{array}{l}17,2 \\
19,1 \\
20,3\end{array}$ & $\begin{array}{l}100 \\
200 \\
200\end{array}$ & $\begin{array}{l}2,0 \\
2,0 \\
2,0\end{array}$ & $\begin{array}{l}20 \\
30 \\
30\end{array}$ & $\begin{array}{c}0,6-0,7 \\
0,6-0,7 \\
0,5-06\end{array}$ & $\begin{array}{l}5-10 \\
9-10 \\
5-10\end{array}$ \\
\hline $\begin{array}{l}\text { Adolescentes } \\
\text { (sexo feminino) } \\
10-12 \text { anos } \\
13-15 \text { anos } \\
16-19 \text { anos }\end{array}$ & $\begin{array}{l}2.350 \\
2.490 \\
2.310\end{array}$ & $\begin{array}{r}9,8 \\
10,4 \\
9,7\end{array}$ & $\begin{array}{l}29 \\
31 \\
30\end{array}$ & $\begin{array}{l}575 \\
725 \\
750\end{array}$ & $\begin{array}{l}2,5 \\
2,5 \\
2,5\end{array}$ & $\begin{array}{l}0,90 \\
1,0 \\
0,9\end{array}$ & $\begin{array}{l}1,4 \\
1,5 \\
1,4\end{array}$ & $\begin{array}{l}15,5 \\
16,4 \\
15,2\end{array}$ & $\begin{array}{l}100 \\
200 \\
200\end{array}$ & $\begin{array}{l}2,0 \\
2,0 \\
2,0\end{array}$ & $\begin{array}{l}20 \\
30 \\
30\end{array}$ & $\begin{array}{c}0,6-0,7 \\
0,6-0,7 \\
0,5-06\end{array}$ & $\begin{array}{r}5-10 \\
12-24 \\
14-23\end{array}$ \\
\hline
\end{tabular}

1 UJ de vitamina A equivale a $0,5 \mu$ de retinol, ou vitamina $A$.

$1 \mu$ de B caroteno equivale a $0,167 \mu$ de retinol, ou vitamina $A$. ** 1 UJ de vitamina D equivale a $0,025 \mu$ de vitamina $D$ pura.

O auxograma do desnutrido grave tem as segumtes características:

a. Idade-altura comprometida com déficit relativo à idade cronologica de 50\%;

b. Idade-peso inferior à idade-altura com déficit relativo à idade cronológica de $75 \%$; no marasmo, a idade-peso pode ser inferior ao nascimento do que resulta-no tempo-um "peso negativo";

c. Idade-óssea acompanhando os parâmetros somáticos e localizando-se entre as idadesaltura e peso; o atraso da idade-óssea sugere que a maturação assoa também está atrasada com conservação do potencial de crescimento;

d. Idade-desenvolvimento atrasada sobretudo nos setores pessoal-social e da linguagem no teste de Gesell.

O comprometimento ósseo na desnutrição traduz-se através dos seguintes aspectos:

1. Sinais de homeostase deficiente de cálcio e fósforo.

a) tendência à hipocalcemia e hipofosfatemia,

b ) tendência para manifestações tetamcas.

2. Sinais de deficiente formação de matriz óssea.

a) osteoporose, b) pouca fireqüência de raquitismo,

c) diminuição da atividade da fosfatase alcalina.

3. Sinais de parada do crescimento e desenvolvimento.

a) imagens radiológicos de "linhas de parada do crescimento",

b) atraso na idade óssea.

\section{Estimulaçao Biopsicossocial}

Os falares psicológicos e de estimulação social de há multo são considerados de grande importância no desenvolvimento neuropsicomotor e intelectual da criança. Mais recentemente, foi reconhecida a importância dos referidos fatores também para o crescimento físico.

A carência afetiva estudada, entre outros autores, por Bakwin, Bowlby e Spitz, consiste na falta de carinho e de solicitação afetiva materna. A necessidade instintiva de receber afeto, atenção e contato físico agradável não é satisfeita e surge assim uma síndrome carencial complexa; as crianças tornaram-se irritadiças e choronas, perdem peso, não têm apetite, seu desenvolvimento neuro-psicomotor se retarda e o crescimento desacelera. 
Durante algum tempo essa síndrome só foi estudada em instituições (hospitais, creches e asilos) e dai o termo hospitalismo. Posteriormente, a síndrome foi evidenciada em falências de nível sócio-econômico baixo e, mais recentemente, também em famílias de nível médio ou superior.

A baixa estimulação biopsicossocial determina, em associação à desaceleração do crescimento, variada gama de distúrbios da conduta: alimentar (ruminação, bulimia, polidipsia), do sono (insónia, vagar pela casa à noite) e de outros selares (enurese, agressividade, crises intensas de birra).

Para explicar os efeitos da carência psicossocial sobre o crescimento físico, Patton e Gardner enumeram as seguintes possibilidades:

a. Baixa de ingestão de dieta adequada, não obrigatoriamente por carência económica, mas sim por problemas afetivos que inclui, entre outros fatores, a negligência,

b. Redução do apetite pela depressão,

c. Diminuição do ácido cloridrico gástrico,

d. Stress emocional interferindo no apetite, digestão, absorção e metabolismo intermediário,

e. A produção de harmónios da hipófise anterior está sob influência de centros hipotalamicos que, por sua vez, recebem estimulação do córtex cerebral e de outras estruturas ligadas às emoções. Na síndrome da baixa estimulação psicossocial, a hipófise não responde aos estímulos habituais no sentido de liberar hormônio de crescimento.

O tratamento da carência afetiva consiste sobretudo na orientação da família no sentido de garantir para a criança segurança afetiva. Em muitos casos, será necessária a psicoterapia dos pais, principalmente a mãe, e nos casos graves pode ser necessário conseguir para a criança uma mãe substituia que dê à criança carinho e apoio emocional. No caso de instituições, o pessoal deverá ser adequadamente treinado e orientado para criar laços afetivos permanentes com as crianças.

Coloca-se, aqui, a situação de milhares de lactentes que permanecem 4 a 8 horas em creches enquanto suas mães trabalham. Embora a creche possa ser considerada uma boa solução para essas fartarias, é importante refletir sobre as condições de estimulação biopsic^qssocial dessas crianças e a responsabilidade dos pais em promovê-la, supletivamente se for o caso, em seus lares.

\section{Atividade Fisica}

A atividade física deve ser encarada sob dois aspectos. Em primeiro lugar, a atividade física não programada, própria das crianças saudáveis e que diz respeito a todas as idades. Há, na realidade, um forte impulso para a atividade física por parte das crianças, sobretudo pré-escolares: eles simplesmente não conseguem permanecer quietos se algo não prender fortemente sua atenção (esse algo tem sido—cada vez mais—o assistir TV). Em segundo lugar, considere-se a atividade física programada, a assim chamada prática esportiva: é aqui que o pediatra, com frequência, é solicitado a opinar quanto à conveniência de a criança praticar continuadamente alguma modalidade de esporte, sob supervisão.

De uma maneira mais abrangente, a educação física (ginástica, jogos, esportes, dança e competição) contribui para o desenvolvimento de:

a. Qualidades puramente físicas como força, flexibilidade, resistência, equilíbrio, velocidade,

b. Qualidades fisico-psiquicas, como capacidade de contração e de relaxamento, bem como coordenação, e

c. Qualidades psicossociais, como força de vontade, disciplina, domínio de si mesmo, coragem, confiança, solidariedade, respeito às leis.

A educação física é, pois, um auxiliar valioso para o aprimoramento do crescimento e do desenvolvimento da criança, nos seus aspectos morfofisiopsicológicos.

A motivação da criança para a prática continua e programada de esportes é muito importante. Até 10 anos, predomina a motivação baseada no prazer e no cantata social com amigos; após essa idade, começa a haver uma preocupação com a competição em si mesma, a busca de sensações cinestésicas ligadas à movimentação do corpo, não se excluindo a relação do esporte corr impulsos sexuais, o esparto desempenhando um papel importante no processo de sublimação próprio da idade. Se o pediatra foi chamado a opinar, ele deve evitar a antiga posição de consideras apto quem não é inapto e tentar levantar os falares ligados à criança (quais suas necessidades e desejos? o que acha da prática desportiva? que esparto prefere?), à família (que expectativa áxis te? o que pensam das atividades competitivas?) e ao local (distan aia, segurança, supervisão).

É de consenso que "um mínimo de atividade muscular e essencial para a obtenção de um crescimento nonnal e a integridade protoplasmática dos tecidos: o que esse anónimo representa em termos de intensidade e duração não está estabelecido", amém certamente decorre de forte impulso para atividade física que todas as crianças apresentam, impulso esse que parece ser uma das grandes necessidades da vida. As crianças hipoativas podem ter prejuízo do seu crescimento, bem como redução de seus potenciais na adulticia, tendência à obesidade e níveis altos de risco de doenças arteriais por toda a vida. Mas, 
em contrapartida, também pode haver problemas físicos e mentais, se a criança, desde a idade escolar, for submetida a treinamento físico intenso competitivo.

No que se refere às ações da atividade física sobre o crescimento e desenvolvimento do esqueleto, há aspectos importantes.

A forma básica do osso é determinada pela herança e está estabelecida embriologicamente na cartilagem. Sabe-se, hoje, que o comprimento do osso está sob forte controle de fatores intrínsecos do crescimento e que o diâmetro é muito mais sensível aos fatores ambientais, entre os quais o exercício físico.

Experimentação animal revela dados interessantes. Os ossos dos membros inferiores de animais imobilizados e denervados mostraram-se mais leves, com menor teor mineral e maior conteúdo hldrico, porém mais compridos e mais finos do que o observado em grupos controles. Radiológica e embriologicamente havia sinais de atividade aumentada na zona epifisária. O aumento em comprimento foi atribuido à ausência de forças compressivas inibidoras do crescimento, e a maior delgadez à remoção dos tendões musculares que constituem um notável estimulo para o crescimento lateralizado dos ossos.

Um dos melhores exemplos de que o crescimento fissão também depende do stress mecanico, é o caso da criança que nasceu sem a sabia em uma das pernas: com a idade de 2 anos, os ortopedistas mudaram a posição do perônio, colocando-o mais no meio da perna, a fim de melhor distribuir o peso corpóreo. Pois bem, 18 meses após a operação, o perônio tinha o aspecto de tíbio A falta da líbia foi um acontecimento ligado à herança (fator intrínseco) e a "tibi lização" do perônio deveu-se ao stress mecanico (fator extrínseco). Esse caso, publicado por Houston, é citado por Bailey. Segundo Evans (citado por Molina) a função-cornpressiva ou tensional-é "o real estímulo pata a formação e o crescimento fissão”. A situação pode ser assim suir rizada:

a. Dentro dos limites de tolerância, o aumento das forças de pressão e tensão determinam formação de novo tecido fissão deu de que atuem sobre superfícies adaptadas para resistir à pressão e à tensão,

b. Aumento de pressão ou tensão além dos limites de tolerancia leva à destruição óssea através da reabsorção,

c. Sempre que a pressão - contínua ou intermitente - interferir com a circulação sangüínea do osso, haverá uma reabsorção osteoblástica do mesmo, conhecidos.
A ausência de suporte de peso corpóreo retarda a restauração de ossos fraturados. O pessoal da missão espacial Gemini, por causa da falta de gravidade, apresentou perda de densidade 6ssea por desrnineralizaçao. As pessoas imobilizadas apresentam elevadas perdas urinarias de cálcio e nitrogénio e consequente diminuição da densidade 6ssea. A situação reverte-se com a remobilização do paciente, mas a correção final do desbalanço pode levar muito tempo. $\mathrm{O}$ desuso leva, pois, à osteoporose, do que resulta a afirmação seguinte: o suporte do peso corpóreo e a contração muscular são importantes para a higidez do esqueleto. Alguns autores lembram que permanecer de pé seja talvez mais importante do que alguns exercícios físicos realizados na posição deitada. Enfim, em termos de manter a mineralização óssea, caminhar é mais importante do que beber leite.

Conclui-se que a compressão energética intermitente, a força da gravidade, o suporte de peso corpóreo e a contraçãa muscular são indispensáveis para o crescimento 6sseo adequado: o excesso parece ser prejudicial. Contudo, não está esclarecido o exato mecanismo através do qual a atividade física promove um melhor crescimento 6sseo: contração muscular, mecanismos neurais ou fatores circulatórios? Mas os pesquisadores aceitam a existência de um fator de crescimento ósseo “exercício-mediado" durante os anos de crescimento da criança.

A idade 6ssea, como índice de avaliação da maturidade, tem sido muito estudada entre préadolescentes e adolescentes praticantes de esportes. A maior parte dos praticantes do sexo masculino apresenta idade 6ssea avançada em relação à idade cronoló gica, o que permite especular em relação à estatura final desses jovens em comparação aos não praticantes. Quanto às meninas, os dados são menos conclusivos, mas a literatura sugere (tanto em relaçao à idade da menarca quanto à idade óssea) haver relação entre maturidade atrasada e desempenho atlético, sobretudo em relação à natação e ginástica. Outros autores afirmam que a relaçao entre idade óssea e desempenho ffsico é mais estreita do que entre idade cronológica, ou altura, ou peso com o desempenho: sugerem que o parametro para dividir em grupos praticantes de espertos entre 10 e 16 anos deve ser a idade 6ssea e não a idade cronológica, principalmente no sexo masculino.

Emerge, então, a questão crucial da idade mínima a partir da qual as crianças podem participar de atividades físicas programadas competitivas, o assim chamado esporte agonístico. Negrão chama a atenção para os inúmeros campeonatos entre crianças, as conhecidas categorias fraldinha, dentinho, dente-de-leite, pré-mirim, mirim, infan- 
til, e que - promovidos por federações esportivas of iciais, bem como por clubes e associaçõesesses campeonatos podem envolver crianças de até cinco anos de idade. Um exemplo claro e atual: o voleibol, esporte de popularidade crescente em função do sucesso da seleção brasileira em campeonatos internacionais. Ainda citando Negrão, o voleibol envolve, em sua prática competitiva, um componente predominantemente anaeróbico lático, isto é, atividade em débito de oxigénio, levando, conseqüentemente, seu praticante a atingir níveis elevados de lactacidermia nos músculos e na circulação sangüinea, bem como alta taquicardia: isso implica em esforços de alta intensidade, entre $80 \%$ e $100 \%$ da condição física máxima, com duração entre 45 segundos e três minutos, para os quais a criança não está devidamente preparada. A atividade anaeróbica lética provoca liberação de catecolaminas e consequente vasoconstrição, do que resulta aumento da força de contração do coração, situação que crianças de baixa idade não superam. A persistência do trabalho anaeróbico Ático nas crianças pode provocar uma hipertrofia precoce da musculatura cardíaca, o que limitará o potencial físico máximo da criança, além de poder predispô-la a uma futura hipertensão arterial. Crianças e adolescentes pré-púberes devem participar de atividades físicas de média intensidade e longa duração (atividade aeróbica, na qual predomina o consumo de oxigénio, com utilização entre $40 \%$ e $80 \%$ da condição física máxima e duração superior a três minutos) e não de alta intensidade e curta duração (atividade anaeróbica).

Tatafiore* lembra que a criança se encontra entre duas situações: a primeira constituída pelas normas sanitárias em relação ao preparo físico pré-agonistico e ao inicio do agonismo; e a segunda representada pelas "lisonjas dos organizadores incompetentes de competições infantis, que estimulam o agonismo até os mais pequenas”, com apoio de autoridades públicas (aspecto politico) e dos próprios familiares (aspecto social). $\mathrm{O}$ agonismo precoce pode levar a criança a um conjunto de alterações somatopsíquicas, os danos do esporte. No campo somático têm sido descritas modificações irreversíveis da relação tronco-membros, hipertrofia cardíaca, pseudonefrite atlética, enfisema e um cortejo de lesões esqueléticas traumáticas. No campo psíquico, citese o aparecimento de tiques, enurese, dificulda- des do aprendizado escplar, repetição de cursos, transtornos do caráter e a síndrome do medo do insucesso.

A idade cronológica não é um bom critério para a decisão de permitir ou não que uma determinada criança participe de competições esportivas: crianças “grandonas” não são obrigatoriamente amadurecidas. Melhor será um critério de ordem biológica, sendo certo a impossibilidade operacional de submeter as crianças a variadas provas funcionais. Dai, a valorização, por muitos autores, como referido antes, da idade 6ssea que nunca deverá ser inferior a 14 anos. Tatafiore sugere como "sinal verde" o aparecimento do osso sesamóide do dedo mínimo.

Finalizando, cite-se Parizková. Nas atuais condições ecológicas e com o presente padrão de vida e de trabalho em muitos paises, encontra-se uma permanente restrição de atividade fisica, isto é, uma hipocinesia prolongada, com seqüelas $\mathrm{i} \wedge$ inportantes como a obesidade e defeitos ortopédicos, sobretudo durante a inf ncia e o início da adolescencia. Há quem afirme que a vida contemporanea não exige maiores aptidões fisicas; entretanto, vale a pena mencionar que um nivel mais elevado de aptidão física e capacidade aeróbica do organismo leva a uma menor fadigabilidade, uma sensação -de bem-estar e, finalmente, à prevenção de várias situações que criam condições para o desenvolvimento de diversas doenças, particularmente as do sistema cardiovascular. O homem contemporaneo está exposto ao stress emocional e, sob sua influência, a reação de alarma desenvolve-se no organismo: ele é a vitima dos anacronismos emocionais e dos estímulos internos que foram indispensáveis para a sobrevida no passado primitivo. Estão envolvidos velhos mecar ismos filogenéticos fixos que, sob condições contemporaneas, levam a uma resposta inoportuna (liberação de catecolaminas, freqüência cardíaca aumentada, débito cardiaco aumentado, elevação da pressão arterial, mobilização maior de ácidos graxos) que constituem a preparacão para a luta ou fuga, isto é, trabalho muscular. Pelo falo desse Irabalho muscular não ser executado, desenvolve-se situações desarmônicas no organismo que são a base das doenças de civilização. Nesse sentido, a atividade física de tipo aeróbico pode ser considerada como fator compensador de alterações metabólicas resultantes de situações estressantes.

\footnotetext{
* Tatafiore lembra que cavalos de raça jamais são treinados para competir antes dos dois anos de idade e somente com três amos participam dos páreos (três amos de cavalo correspondem a 15 anos para o ser humano). Pois bem, a nmguém ocorre submeter potrinhos a esforços imcompatíveis com sua idade, mas, em relação a crianças é um verdadeiro vale-tudo, sob a responsabilidade, ou melhor, sob a irres $\mathrm{P}^{\wedge} \wedge$ Dsabilidade de autoridades, treinadores e familiares.
} 
A importância de um bom esquema para as crianças em rãlação à atividade física, um dos mais importantes falares ambientais na garantia de 6tirno desenvolvimento da função e da saúde, já foi explicitada há muito tempo:

\begin{abstract}
Quanto mais a criança está dedicada a alguma coisa, brincando com liberdade, ocupada em fazer algo, tanto mais suave o seu sono, mais fácil sua digestão, mais precioso seu crescimento, tornando-se forte e desenvolvendo-se tanto corporal como mentalmente, devendo-se protegê-la exclusivamente de lesões. Para essa finalidade, deve-se procurar e encontrar um lugar seguro onde a criança possa correr livremente e exercitar-se, devendo-se mostrar um modo inofensivo para tais exercícios. (Escrito por John Amos Comenius, no ano de 1632).
\end{abstract}

\section{Variação Secular do Crescimento}

Possivelmente, como resultado conjunto dos fatores ambição tais, tem sido possível comprovar uma nítida tendência, com o correr dos anos, para a aceleração do crescimento e desenvolvimento, tanto no selar físico (estatura cada vez mais elevada para uma determinada idade) como na maturidade biológica (por exemplo, menarca em idades cada vez mais precoces).

A causa da aceleração secular do crescimento ainda não foi definitivamente esclarecida. Metedith relaciona as seguintes: maior participação em atividades esportivas, menor rnorbidade, urbanização, imigração, diminuição do trabalho do menor, melhoria da higiene da comunidade e das habitações, vestuário menos restritivo, aumento da ingestão de nutrientes, melhoria dos cuidados médicos, mudanças na umidade e temperatura do planeta, tendência evolucionista para os organismos de um pkyl m aumentarem o seu tamanho, expressão curnulativa da heterose, diminuição do tamanho das famílias.

Os dados na literatura sugarem fortemente que a aceleração do crescimento tem algo a ver com a urbanização, pois ela é mu to mais intensa nos centros urbanos do que na zona rural. Não há dúvida que a urbanização está modificando a organização psicobi ${ }^{\wedge} \mathbf{0}^{\wedge}{ }^{\wedge}$ lógi ${ }^{\wedge}$ ca do ser humano, e a ciência que deve assumir as responsabilidades de clarear o assunto é a antropologia. Ela nos informa sobre a aceleração mental determinada pelos estímulos urbanos; a "desnaturalização biológica” que se processa na forma,cão das comunidades urbanas; a dilatação da vida fértil (menarca mais precoce e menopausa mais tardia); a tipificação do homem nas grandes cidades. A intensificação do crescimento que foi verificada no pós-guerra significa não somente modificações do corpo, mas também uma definitiva aceleração na maneira de encarar e sentir o meio-ambiente, do que resulta ser essa nova criança capaz de adquirir experiências de um modo muito diferente do observado nas crianças em épocas anteriores. A esse conjunto de influências, Takai reserva a denominação trauma da urbanização, capaz de modificar a sensibilidade dos 6rgaos efetores aos estimulos do crescimento, através-talvez-do sistema límbico. Contudo, a resposta favorável em termos de aceleração do crescimento to sé existirá se houver adequado aporte nutricional.

\section{COMENTARIOS FINAIS}

Wolanski refere que o crescimento é um processo formativo de estruturas e funções conforme certas leis da genética, bem como das condições de vida: o conjunto ambientar consiste de um complexo de fatores biogeográficos, modificado, no homem, pelas condições sócio-econômicas. É sob a influência de fatores genéticos específicos e do seu meio-ambiente que o homem atinge, primeiro, sua maturidade individual e, em seguida, a maturidade da espécie, isto é, a capacidade reprodutora. A antrolologia talvez possa resolver alguns dos problemas fundamentais da auxologia:

1. Estabelecimento de diferentes respostas de individuos genotipicamente diferentes (com definidos fenótipos) aos mesmos fatores ambientais, ou vice-versa, as reações de indivíduos genotipicamente iguais e diferentes condições arnbientais;

2. Estabelecimento das condições ambientais ótimas em relação à especificidade genotípica, isto é, integração coordenada dos fatores endógenos e exógenos (compatibilidade molecular entre os determinantes paternos e maternos, e a influência ambiental na produção de enzimas, por exemplo); e

3. Estabelecimento das modificações da sensibilidade tissular responsável pelas diferentes respostas em diferentes periodos do crescimento.

As combinações ambientais que podem influenciar o crescimento são inimigas (figura 1). A partir do tecido uterino que cerca o ovo nidado, o ambiente expande-se continuamente por força da necessidade que o homem tem de explorá-lo, sendo certo que, no presente momento, a exploração ambiental já atingiu o despacho sideral.

A partir de uma certa idade, variável de indivíduo para indivíduo, o meio-ambiente começa a retrair-se e o homem, em sua velhice, busca a segurança de sua cidade, e depois de sua casa e 


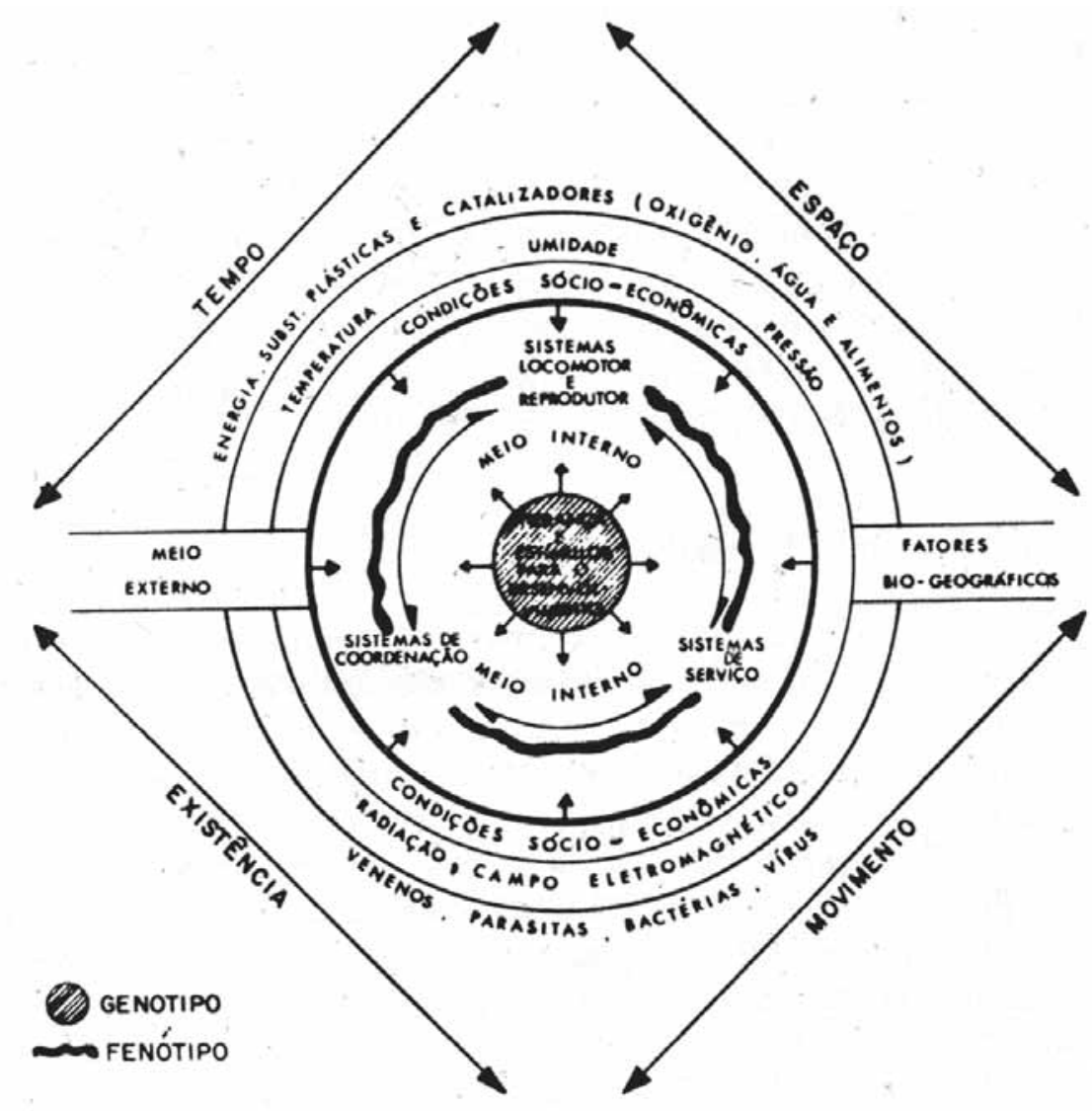

Figura 1 - Interação dos fatores do crescimento (modificado de Wolanski, 1967).

de seu dormitóno. Nossa última morada, o túmulo, assemelha-se em parte, à nossa primeira morada, o útero matemo.

O ambiente é uma força extremamente poderosa na filogênese, capaz de determinar a freqüência de genes através dos vários mecanismos controladores da população e por isso, capaz de definir os limites para o aparecimento de novos padrões genotípicos, através de mutações. Em outras palavras, o ambiente é a fonte primeira e última da variabilidade do crescimento dos seres vivos.

O crescimento está em contínua homeostase biopsicossocial com sua dinâmica (fatores e processo), sua cinética (o fenômeno em si mesmo) e sua energética (nutrição e estimulação). E por ser contínuo na vida do indivíduo, em seus desdobramentos tissulares e celulares, bem como no suceder das gerações, cabe afirmar que o crescimento da criança é um momento e não um estado; em termos auxológicos, a criança está e não é, o que bem aponta o conteúdo antropológico do fenômeno.

\section{BIBLIOGRAFIA}

1. BAILEY, D. A. Exercise, Essa and physical education for lhe growing child. A concerned Canad. J. Public Health 64: 421 430, 1973.

2. BAILEY, D. A.; MALTINA, Á. M.; RASMUSSEN, R. L. The influence of exercise, physical activity Ad athletic performance on the dynamics of human growth. In: Falkner, F. \& Tanner, J. M. (eds.). Human Growth. 2. Postnatal Grow h. New York, Plenum Press, 1978.

3. BAKWIN, H. Emotional deprivation in infanta. $J$. Pedias. 35: 512-521, 1949.

4. BENNETT, S. W. \& CARCAVALLO, R. V. Sistemas ecológicos y salud humana. Bol. Of. Sanit. Panamer. 86: 1-9, 1979.

5. BOWLBY, J. Los cuidados maternos y la salud mental. Publicación Científica $n^{\circ} 164$. Washington, OPAS, 1968.

6. CHAVES, M. M. Saúde. Uma Estratégia de Mudanças. Rio de Janeiro, Guanabara Dois, 1982.

7. CUMMING, G. R.; GARAND, T.; BORYSK, L. Correlation of performance in track and field events with bone age. J. Pediat. 80: 97 973, 1972.

8. GALBO, H. Hormonal and Metabolic Adaptation to Exercise. New York, Thieme-Stratton, 1983. 
9. HABICHTT J. P. et al. Height and weight for preschool children. How relevant are ethnic differences in growth potential? Lancet 1: 611-614, 1974.

10. MOLINA, R. M. Exercise as an influence upon growth. Review and critique of current concepts. Clin. Pediat. 8: 16-26, 1969.

11. MARCONDES, E. (coord.). Crescimento Normal e Deficiente. $2^{\mathrm{a}}$ ed., São Paulo, Sarvier, 1978.

12. MARCONDES, E., BERQUÓ, E.; HEGG, R., COLLI, A. S., ZACCHI, M. A. S. Crescimento e Desenvolvimento Pubertário em Crianças e Adolescentes Brasileiros. I - Metodologia. São Paulo, Edit. Bras. Ciências, 1982.

13. MARCONDES, E. Normas para o diagnóstico e classificação dos distúrbios do crescimento e do estado nutricional. Ultima versão. Pediat. 4: 307326, São Paulo, 1982.

14. Marcondes, E. Semiologia do crescimento deficiente: roteiro diagnóstico. Pediat. 5: 19-32, São Paulo, 1983.

15. MARCONDES, E. (coord.). Ecopediatria. A Força do Arnbiente sobre a Saúde da Criança. São Paulo, Sarvier, 1981.

16. MARCONDES, E. Atividade física e crescimento. Pediat. 7: 51-60, São Paulo, 1985.

17. MARCONDES, E. Crescimento e desenvolvimento da criança. In Nóbrega, F. J. \& Leone, C. (eds.). Assistência Primária em Pediatria. São Paulo, Artes Médicas. No prelo.

18. MARQUES, R. M.; MARCONDES, E.; BERQUÓ, E.; PRANDI, R.; YUNES, J. Crescimento e Desenvolvimento Pubertario em Crianças e Adolescentes Brasileiros. 11 - Altura e peso. São Paulo, Edit. Bras. Ciências, 1982.

19. MEREDITH, H. B. Findings from Asia, Australia, Europe and North America on secular change in mean height of children, youth and young adults. Amer. J. Phys. Antrop. 44: 315-325, 1976.

20. MARSHALL, W. A. Geographical and ethnic variations in human growth. Brit. Med. Bull. 37: 265-279, 1981.

21. MARTORELL, R. et al. Diarrheal disease and growth retardation in preschool Guatemalan children. Amer. J. Phys. Antrop. 43; 341-346, 1975.

22. MONGE, C. Ecology and health. Bull. Amer. Health Org. 12: 7-10, 1978
23. NEGRÃO, C. E. Os mini-campeões. Cad. Pesq. 34: 29-33, São Paulo, 1980.

24. OLIVEIRA, T.; MOURÃO, F. A. A.; MARCONDES, E. Crescirnento físico de crianças faveladas no município de São Paulo. J. Ped. 38: 256-264, Rio de Janeiro, 1973.

25. PAR1ZKOZA, J. Gordura Corporal e Aptidão Física. Rio de Janeiro, Guanabara Dois, 1982.

26. PATTON, R. G. \& GARDNER, L. I. Short stature associated with maternal deprivation syndrome: disordered family envinronment as cause of socalled idiopathic hypopituitarism, In:- Gardner, L. I. (ed.). Endocrine and Genetic Diseases of Childhood and Adolescense. Philadelphia, Saunders, 1969, pp. 77-89.

27. RAMOS GALVAN, R. Somatometria pediátrica. Estudio semilongitudinal en ninos de la Ciudad de Mexico. Arch. Invest. Med. 6 (supl. 1): 83-386, 1975.

28. SPITZ, G, R. A. El Primer Año de Vida. Madrid, Aguilar, 1961.

29. TAKAY, T. Somatic growth in Japan. Memórias do XII Congresso internacional de Pediatria. México, 1986.

30. TATAFIORE, E. Aspectos médicos e auxológicos do esporte na infancia. Gazeta Sanit. 3: 125-128, Fundação Carlo Erba, 1968.

31. TOLENTINO, P. Classificazione, patogenetica dei disturbi dell accrescimento da malattie infettine e parassitaire. Min. Ped. 26: 605-609, 1974.

32. UNICEF. Situação Mundial da Criança - 1984. Brasília, 1984

33. UNICEF. Situação Mundial da Criança - 1986. Brasília, 1986.

34. WOLANSKI, N. Environmental modification of human form and function. Ann. N. Y. Acad. Sci. 134: 826-840, 1966

35. WOLANSKI, N. Basic problems in physical development in man in relation to the evaluation of development of children and youth. Current. Anthr. 8: 35-60, 1967.

36. WOLANSKI, N. \& TOMONARI, K. Main problems of human ecology connected with the requirements of developmental Medicine. J. Hum. Eeol. \& Raee Hyg. 39: 146-156, 1973 